\title{
Fuzzy multi-attribute decision making evaluation of e-learning websites using FAHP, COPRAS, VIKOR, WDBA
}

\author{
Rakesh Garg $^{\mathrm{a}^{*}}$ and Dimpal Jain ${ }^{\mathrm{a}}$
}

${ }^{a}$ Hindu College of Engineering, Sonepat, Haryana, India

\begin{tabular}{l}
\hline C H R O N I C L E \\
\hline Article history: \\
Received September 16, 2016 \\
Received in revised format: \\
October 22, 2016 \\
Accepted February 22, 2017 \\
Available online \\
February 22 2017 \\
\hline Keywords: \\
FMADM \\
FAHP \\
COPRAS \\
VIKOR \\
WDBA
\end{tabular}

A B S T R A C T

\begin{abstract}
The present paper emphasizes on the development of a hierarchical model using Fuzzy Multiple Attribute Decision Making (FMADM) method for the selection of E-learning websites. The working of the model developed in this research mainly consists of three steps: (i) Summarization and identification of selection indexes, (ii) Selection indexes weights calculations using Fuzzy Analytical Hierarchy Process (FAHP) and (iii) Ranking of alternatives by implementing three MADM analytical methods as Complex Proportional Assessment (COPRAS), Visekriterijumsko Kompromisno Rangiranje (VIKOR) and Weighted Distance Based Approximation (WDBA). In order to demonstrate the applicability and utility of the proposed methods, an empirical example related to the selection of E-learning websites that are widely used to learn the ' $C$ ' Programming Language for the software development is carried out. In addition, the results of these three methods are also compared to analyze the critical aspects of the selection indexes. It strongly shows that the developed FMADM model
\end{abstract} of this paper could be an efficient and effective assessment tool.

\section{Introduction}

The rapid advancements in the information technology has introduced very highly efficient and effective way of learning and teaching, termed as electronic learning (E-learning). E-learning is referred as a learning process that utilizes electronic technology to access the educational curriculum outside of the traditional classroom. Simply, it can be stated that electronic learning is essentially a network enabled technology for the transfer of knowledge to the learners that include various concepts such as virtual classrooms, computer and internet based learning. Mahanta and Ahmed (2012) provided a technology to transfer the knowledge and skills to people by digital collaboration, web-based learning and computer-based learning. The main emphasis of the E-learning is on the enhancement of the learning and teaching process so that learners would be more capable to understand the various things

\footnotetext{
* Corresponding author. Tel.: +91-9416907980

E-mail address: rkgarg06@gmail.com (R. Garg)

(C) 2017 Growing Science Ltd. All rights reserved. doi: $10.5267 /$ j.dsl.2017.2.003
} 
more easily and precisely. In E-learning, information is delivered to the learners by through the electronic medium via internet, CD-ROM and DVD (Covella \& Olsina, 2002).

In the present scenario, E-learning generates an effective learning for better education and provides a great opportunity for the students to gain knowledge at any place and any time without any compulsion for attending the classroom. Some companies and organizations do not afford the number of trainers due to some financial problems, so they implement the concept of E-learning due to its potential benefits such as cost saving, improving the learning contents and reducing the role of face-to-face learning. According to Zaman et al. (2012), the success of E-learning systems depends on content, service and system. Now a day, the popularity of E-learning websites has grown at a very rapid rate, so it becomes more difficult to select the best E-learning website among the available ones. This paper solves the E-learning websites evaluation and selection problem using the multi-attribute decision making methods. The three MADM analytical methods, namely COPRAS, VIKOR and WDBA are adopted to solve the present problem. These approaches have significant advantages such as easy to understand, no limit of the number of alternatives and selection indexes weights consideration, etc.

The framework of this manuscript is prepared in six sections as follows. Section 2 provides the various selection indexes and methods used for the E-learning websites evaluation and selection in the past. Section 3 describes the hierarchical framework of the present problem and proposed methods to solve the present problem. Section 4 shows the applicability of the proposed methodologies and an empirical example is presented. Section 5 covers the discussion of the results and finally, last section i.e. Section 6 gives the conclusion and future recommendations of the present problem.

\section{Selection indexes and methods in past}

A large number of MADM techniques have already been applied by researchers to solve the E-learning website selection problem. Volery and Lord (2000) considered three main success factors, namely previous use of technology, instructor and technology for the E-learning systems. Blanc and Wands (2001) addressed three main success factors for E-learning, including cognitive factors, organizational factors and general factors. Soong et al. (2001) considered a number of critical success factors, namely human factors, cooperation level, technical competency of students and teachers, IT infrastructure and attitude of student and teacher for the E-learning system. Govindasamy (2002) discussed seven Elearning parameters, i.e. faculty support, student support, course development, evaluation and assessment, course structure, teaching and learning and institutional support for the implementation of effective systems. Ehlers (2004) considered seven different quality fields such as the selection criteria, namely tutor support, didactics, costs-expectations-benefits, technology, course structure, collaboration and information transparency of course for the E-learning system. Pruengkarn et al. (2005) presented the functionality, efficiency, portability, reliability, maintainability and usability such as the selection criteria for the E-learning system. Selim (2007) identified four E-learning success factors, i.e. university support, student characteristics, technology infrastructure and instructor characteristics from the student point of view. Ozkan and Koseler (2009) developed a model named HELAM for the evaluation of Learning Management Systems (LMS) using six dimensions, namely instructor attitudes, learner perspective, supportive issues, content quality, service quality and system quality. Sela and Sivan (2009) proposed nine E-learning success factors, i.e. incentives, time to learn, mandatory usage, real need, management support, ease of use, organizational culture, marketing and support. The extensive study of Vukovac et al. (2010) is to consider the two selection criteria such as general criteria and Elearning specific criteria for the evaluation of usability in E-learning system. Mosakhani and Jamporazmey (2010) anticipated the critical success factors in seven categories, i.e. knowledge management, content, educational institutes, information technology, instructor characteristics, participations interaction and student characteristics for the E-learning systems. FitzPatrick (2012) developed five main key success factors, i.e. evaluation, support, technology, human and design for the evaluation of E-learning in higher level education. Alias et al. (2012) identified ten dimensions, i.e., 
linkage, support, communication, structure and layout, information, efficiency, appearance, reliability, ease of use and security to ensure the success of E-learning in higher education from a student's perspective. XaymoungKhoun et al. (2012) used two methodologies i.e. analytical hierarchy process (AHP) (Saaty, 1980) and Delphi method for the prioritization of success factors in E-learning system. The study mainly focused on seven dimensions, i.e. infrastructure and system quality, motivation, instructor characteristics, environment, learner's characteristics, course and information quality and institution and service quality. Cheawjindakarn (2013) identified five critical success factors, namely course evaluation, instructional design, institutional management, services support and institutional management for the online distance learning. Oztekin et al. (2013) proposed a new method called machine learning method based on usability evaluation of the E-learning system.

Yunus and Salim (2013) developed a model called E-learning evaluation model. This study considered eleven evaluation criteria, namely knowledge transfer and theory objective learning outcome, learnerlearner, learner-instructor, learner- content, learning style, motivation and attitude, structure dimension, instruction and help, multimedia design, content and interactivity, and interface design for the effective evaluation of E-learning system. Ozturk (2014) proposed an analytical network problem (ANP) approach for the prioritization of criteria, i.e. learner, evaluation, learning media, physical facilities, instructor, academic counseling, alternatives and administration in distance and open learning programs. Aparicio et al. (2016) anticipated a theoretical framework for an E-learning system based on three dimensions services, users and technology. Jain et al. (2016) proposed a WDBA approach for ranking of E-learning websites by using seven selection criteria, namely security, user interface, right and understandable content, navigation, interactivity, personalization and complete content. The extensive study of the literature review reveals that the present problem of selection of E-learning websites can be described more precisely by describing it as a MADM problem.

\section{Evaluation framework development and proposed MADM methods}

The hierarchical model of the present problem is represented in Fig. 1. A performance analysis is carried out based on ten selection indexes, namely functionality, maintainability, portability, reliability, usability, efficiency, ease of learning community, personalization, system content and general factors. Firstly, the fuzzy AHP (FAHP) approach is utilized to calculate the weights of the selection indexes. Then, three MADM analytical methods, namely COPRAS, VIKOR and WDBA are proposed to rank the various alternatives i.e. E-learning websites. The fuzzy set theory and three MADM methods are described further in the subsequent sections.

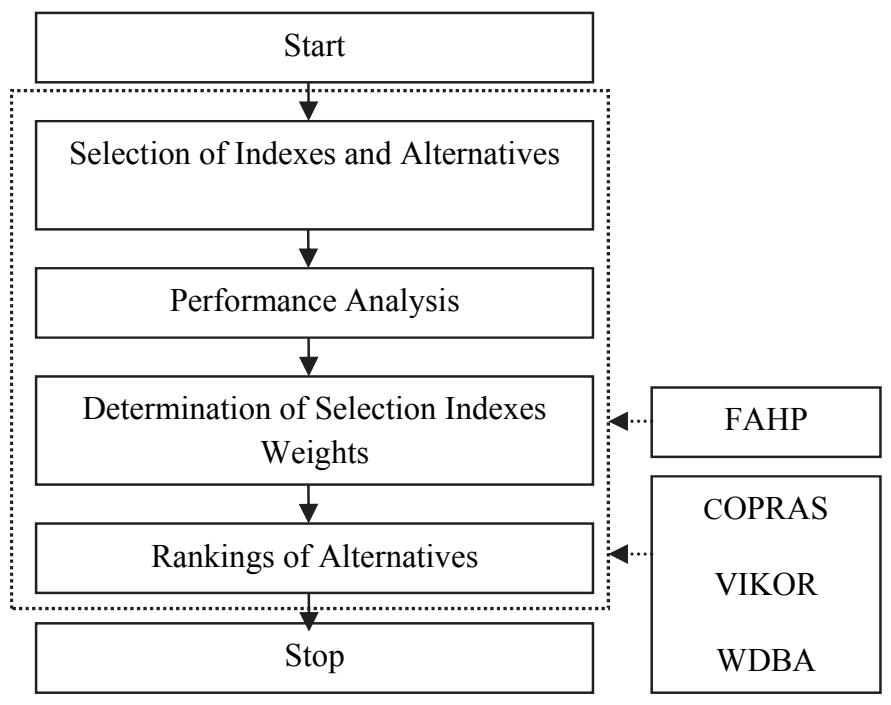

Fig. 1. Proposed evaluation framework 


\subsection{Fuzzy sets and numbers}

The fuzzy set theory was first introduced by Zadeh (1965) to deal with the vagueness of the data. A fuzzy set is an ordered pair $(F, x)$ where $F$ is a set and $x: F \rightarrow[0,1]$ i.e. membership function. Fuzzy set theory has already applied in various areas, i.e. scientific environment, control theory, robotics, etc. A triangular fuzzy number (TFN) is usually used to deal with the vagueness of the data which is related to the performance of alternatives with respect to each index. A TFN defined by triplet $T=(u, v, w)$ can be expressed as Eq. (1). The representation of TFN membership function is shown in Fig. 2.

$$
\mu_{A}(x)= \begin{cases}(x-u) /(v-u) & \text { if } u \leq x \leq v, \\ (w-x) /(w-v) & \text { if } v \leq x \leq w, \\ 0 & \text { otherwise. }\end{cases}
$$

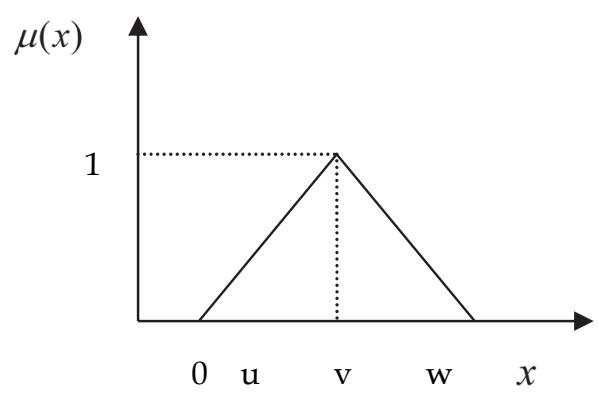

Fig. 2. Triangular fuzzy number membership function

Consider any two triangular fuzzy numbers $\mathrm{T}_{1}=\left(u_{1}, v_{1}, w_{1}\right)$ and $\mathrm{T}_{2}=\left(u_{2}, v_{2}, w_{2}\right)$. Some algebraic operations of the TFNs $T_{1}$ and $T_{2}$ can be represented as:

Addition, Subtraction and Multiplication ' $\oplus$ ' can be represented as:

$$
T_{1} \oplus T_{2}=\left(u_{1}+u_{2}, v_{1}+v_{2}, w_{1}+w_{2}\right) \quad T_{1} \oplus T_{2}=\left(u_{1}-w_{2}, v_{1}-v_{2}, w_{1}-u_{2}\right) \quad T_{1} \oplus T_{2}=\left(u_{1} u_{2}, v_{1} v_{2}, w_{1} w_{2}\right)
$$

\subsection{Fuzzy analytical hierarchy process (FAHP)}

Analytical Hierarchy Process (AHP), was first proposed by Saaty (1980), and has been widely used to solve the complex multi-criteria decision making problems. This approach has been successfully applied to solve a number of MADM problems concerning to different areas such as vendor selection, strategic planning, resource allocation, etc. AHP is a measurement of theory through pair-wise comparisons and relies on the expert choice using the (1-9) point scale. In this research, FAHP is used to calculate the selection indexes weight. The steps involved in the AHP method are described below:

Step 1: Construct the hierarchal framework: In this study, first level of the hierarchy defines the goal of the present problem. The second level of the hierarchy consists of indexes. These indexes are decomposed into the various sub- indexes at the third level.

Step 2: Construct the matrices of fuzzy pair-wise comparisons: In this step, fuzzy pair-wise comparison matrices are constructed for all the selection indexes using the one to nine point scales as shown in Table 1.

$$
A=\left[\begin{array}{cccc}
1 & a_{12} & \cdots & a_{1 n} \\
a_{21} & 1 & \cdots & a_{2 n} \\
\vdots & \vdots & \ddots & \vdots \\
a_{n 1} & a_{n 2} & \cdots & 1
\end{array}\right]
$$


where $a_{i j}=\left(u_{i j}, v_{i j}, w_{i j}\right)$ is the fuzzy pair-wise comparison value of $i^{\text {th }}$ index to $j^{\text {th }}$ index.

\section{Table 1}

Linguistic variables with their triangular fuzzy numbers

\begin{tabular}{llll}
\hline Importance of Scale & Description & TFN's & Reciprocal of TFN's \\
\hline 1 & Equally Important & $(1,1,1)$ & $(1,1,1)$ \\
3 & Moderately Important & $(2,3,4)$ & $(1 / 4,1 / 3,1 / 2)$ \\
5 & Strong Important & $(4,5,6)$ & $(1 / 6,1 / 5,1 / 4)$ \\
7 & Very Strong Important & $(6,7,8)$ & $(1 / 8,1 / 7,1 / 6)$ \\
9 & Extremely Important & $(9,9,9)$ & $(1 / 9,1 / 9,1 / 9)$ \\
\hline
\end{tabular}

Step 3: Compute the fuzzy weights of each index: The fuzzy weights of each index can be computed as Eq. (2) and Eq. (3), where $R_{i}^{\sim}$ is the geometric mean of the fuzzy pair-wise comparison value of $i^{\text {th }}$ index to each index and $W_{i}^{\sim}$ is the fuzzy weight of the $\mathrm{i}^{\text {th }}$ index.

$$
\begin{aligned}
& R_{i}^{\sim}=\left(a_{i 1} \otimes a_{i 2} \otimes \ldots \ldots . \otimes a_{i n}\right)^{1 / n} \\
& W_{i}^{\sim}=R_{i}^{\sim} \otimes\left(R_{1}^{\sim} \oplus R_{2}^{\sim} \oplus \ldots \ldots \oplus R_{n}^{\sim}\right)^{-1}
\end{aligned}
$$

\subsection{COPRAS method}

COPRAS methodology was first proposed by Zavadskas et al. (1994). In this method, alternatives are evaluated against the index and ranked according to the fitness degree. The alternative to having the maximum value of the fitness degree is ranked at first position and the alternative having the minimum value of the fitness degree is ranked at last position. COPRAS method is a MADM based approach and applied in many areas as stock selection, vendor selection, etc. The COPRAS method steps are represented below:

Step 1: Create the decision rating matrix $D=\left[d_{i j}\right]_{m \times n}$ where $\mathrm{d}_{\mathrm{ij}}$ is the ratings of the $\mathrm{i}^{\text {th }}$ alternative on the $\mathrm{j}^{\text {th }}$ index, m: no. of alternatives and $\mathrm{n}$ : no. of indexes.

Step 2: Normalized the decision rating matrix $(\mathrm{N})$ and determine the weighted rating matrix $(\mathrm{W})$ using the following Eq. (4) and Eq. (5).

$$
\begin{aligned}
& N=\left[n_{i j}\right]=d_{i j} / \sum_{i=1}^{m} d_{i j} \\
& W=n_{i j} \cdot \mathcal{W}_{j}
\end{aligned}
$$

Step 3: The sum of weighted rating matrix is calculated for beneficial and non-beneficial attributes by using the Eq. (6) and Eq. (7).

$$
\begin{aligned}
& B^{+i j}=\sum_{j=1}^{n} W_{+i j} \\
& B^{-i j}=\sum_{j=1}^{n} W_{-i j}
\end{aligned}
$$

Step 4: Calculate the relative preference $\left(\mathrm{P}_{\mathrm{i}}\right)$ and fitness degree $\left(\mathrm{F}_{\mathrm{i}}\right)$ values for the $\mathrm{i}^{\text {th }}$ alternative by using the Eq. (8) and Eq. (9). 


$$
\begin{aligned}
& P_{i}=B^{+i j}+\frac{B_{- \text {min }} \sum_{i=1}^{m} B^{-i j}}{B^{-i j} \sum_{i=1}^{m} \frac{B-\min }{B^{-i j}}} \\
& F_{i}=\frac{P_{i}}{P_{\text {max }}} \times 100 \%
\end{aligned}
$$

\subsection{VIKOR method}

VIKOR method was created by Opricovic (1998) and also known as a compromise ranking method. This method determines the solution that is nearest to the ideal solution. VIKOR method is based on the multi-criteria optimization of complex problems. The main motive of VIKOR method is to find out the positive and negative solutions. The positive solution means the best value of alternatives against the index and negative solution means the worst or least value of alternatives. The steps involved in the VIKOR method are presented below:

Step 1: Create the performance rating matrix $\left(\mathrm{P}_{\mathrm{ij}}\right)$ and then, calculate the best and worst values for all the indexes by using the Eq. (10) and Eq. (11).

$$
P_{i j}=\left[\begin{array}{cccc}
p_{11} & p_{12} & \cdots & p_{1 n} \\
p_{21} & p_{22} & \cdots & p_{2 n} \\
\vdots & \vdots & \ddots & \vdots \\
p_{m 1} & p_{m 2} & \cdots & p_{m n}
\end{array}\right]
$$

$$
\begin{aligned}
& B_{j}{ }^{+}={ }_{i}^{\max } P_{i j} \\
& B_{j}{ }^{-}={ }_{i}^{\mathrm{min}} P_{i j}
\end{aligned}
$$

Step 2: Calculate the utility measure $\left(\mathrm{U}_{\mathrm{i}}\right)$ and regret measure $\left(\mathrm{R}_{\mathrm{i}}\right)$ for all the alternatives by using the following Eq. (12) and Eq. (13).

$$
\begin{aligned}
U_{i} & =\sum_{j=1}^{n}\left[w_{j}\left(B_{j}^{+}-P_{i j}\right) /\left(B_{j}^{+}-B_{j}^{-}\right)\right], \\
R_{i} & ={ }_{j}^{\max }\left[w_{j}\left(B_{j}^{+}-P_{i j}\right) /\left(B_{j}^{+}-B_{j}^{-}\right)\right],
\end{aligned}
$$

where $i=1,2, \ldots, m:$ no. of alternatives, $j=1,2, \ldots, n$ : no. of indexes and $w_{j}$ is the weight of $\mathrm{j}^{\text {th }}$ index.

Step 3: Next, compute the gaps $\left(\mathrm{S}_{\mathrm{i}}\right)$ for all the alternatives by using the Eq. (14), where $U^{+}={ }_{i}^{\min } U_{i}$, $U^{-}={ }_{i}^{\max } U_{i}, R^{+}={ }_{i}^{\min } R_{i}$ and $R^{-}={ }_{i}^{\max } R_{i}$. In this research, the value of $\mathrm{v}$ is set to 0.5 where $\mathrm{v}$ and $(1-\mathrm{v})$ is the weight for the group utility and individual regret.

$$
S_{i}=v\left[\frac{\left(U_{i}-U^{+}\right)}{\left(U^{-}-U^{+}\right)}\right]+(1-v)\left[\frac{\left(R_{i}-R^{+}\right)}{\left(R^{-}-R^{+}\right)}\right]
$$

Step 4: Now, rank the alternatives by sorting the values of $U_{i}, R_{i}$ and $S_{i}$ in decreasing order. Finally, we get the three ranking lists, i.e. $U_{i}, R_{i}$ and $S_{i}$. 
Step 5: Propose as a compromise solution; alternative $\left(\mathrm{a}_{1}\right)$ ranks at the first position by $\mathrm{S}_{\mathrm{i}}(\mathrm{min})$ if following two given conditions are fulfilled:

Condition-1: Acceptable advantage

$$
S_{i}\left(a_{2}\right)-S_{i}\left(a_{1}\right) \geq A S_{i} A S_{i}=1 / N-1
$$

where $\left(\mathrm{a}_{2}\right)$ is the alternative which is ranked at second highest position in the ranking list by $\mathrm{S}_{\mathrm{i}}$ and $\mathrm{N}$ is the number of alternatives.

Condition-2: Alternative $\left(\mathrm{a}_{1}\right)$ is stable within the decision-making process, i.e. alternative $\left(\mathrm{a}_{1}\right)$ is also ranked in first position by $U_{i}$ and $R_{i}$. If one of the above conditions is not fulfilled properly, then a set of compromise solutions will be proposed that mainly consists of:

(1) If condition-2 is not fulfilled, then the alternatives $\left(a_{1}\right)$ and $\left(a_{2}\right)$ are compromise solutions.

(2) If condition- 1 is not fulfilled, then the alternatives $a_{1}, a_{2}, \ldots \ldots, a_{m}$ are compromise solutions where $\mathrm{a}_{\mathrm{m}}$ is determined by this relation $S_{i}\left(a_{m}\right)-S_{i}\left(a_{1}\right)<A S_{i}$ for maximum $\mathrm{m}$. Finally, the alternative is ranked on the basis of $S_{i}$ value; the alternative having the minimum value of $S_{i}$ ranks at the first position.

\subsection{WDBA method}

WDBA method is applied for the ranking of ' $C$ ' programming language websites. This approach measures the weighted distance from the optimal point (best value of alternatives) and non-optimal point (worst value of alternatives). In this approach, the ranking of ' $\mathrm{C}$ ' programming language websites is performed based on the suitability index. WDBA approach has already been applied in many fields as plant layout design (Rao \& Singh, 2012), Inventory policies selection (Gupta et al., 2013), COTS component selection (Garg et al., 2016), E-learning websites selection (Jain et al., 2016). The steps of WDBA method are given below.

Step 1: Create the decision rating matrix $\left(\mathrm{D}_{\mathrm{ij}}\right)$, where $i=1,2, \ldots, m, j=1,2, \ldots, n$ represent the ratings of $i^{\text {th }}$ alternative on the $j^{\text {th }}$ index.

Step 2: Determine the weighted decision rating matrix (W) by using the Eq. (15), where $\mathrm{w}_{\mathrm{j}}$ is the weight of $j^{\text {th }}$ index.

$$
W=D_{i j} \times w_{j}
$$

Step 3: Formation of standardized matrix $\left(\mathrm{SM}_{\mathrm{ij}}\right)$ using the Eq. (16) to Eq. (18), where $\mathrm{a}_{\mathrm{ij}}$ - adjusted matrix, $\overline{v_{j}}$ - average value and $\mathrm{SD}_{\mathrm{j}}-$ standard deviation.

$$
\begin{aligned}
& S M_{i j}=\frac{a_{i j}-\overline{v_{j}}}{S D_{j}} \\
& \overline{v_{j}}=\frac{1}{n} \sum_{i=1}^{n} a_{i j} \\
& S D_{j}=\left[\frac{1}{n} \sum_{i=1}^{n}\left(a_{i j}-\overline{v_{j}}\right)^{2}\right]^{1 / 2}
\end{aligned}
$$

Step 4: Calculate the distance matrix and composite distance matrix. Finally, the suitability index (SI) values are obtained by using the Eq. (19).

$$
S I=\sqrt{\sum_{j=1}^{n}\left(C D_{i j}\right)}
$$




\section{An empirical example}

\subsection{Hierarchical framework for selection indexes}

Through the extensive study of literature review, 75 selection indexes were summarized and then a screening process comprising of experts questionnaire was adopted to find the most suitable selection indexes that can contribute in the evaluation process of E-learning websites. Finally, total 10 selection indexes were identified and categorized into the two categories as, "A1: Quality factors (C1-C6)" and "A2: E-learning specific factors (C7-C10)" by the team of experts, comprised of ten professionals from the industry and the academia. The hierarchical structure of the E-learning website selection indexes is shown in the Fig. 3.

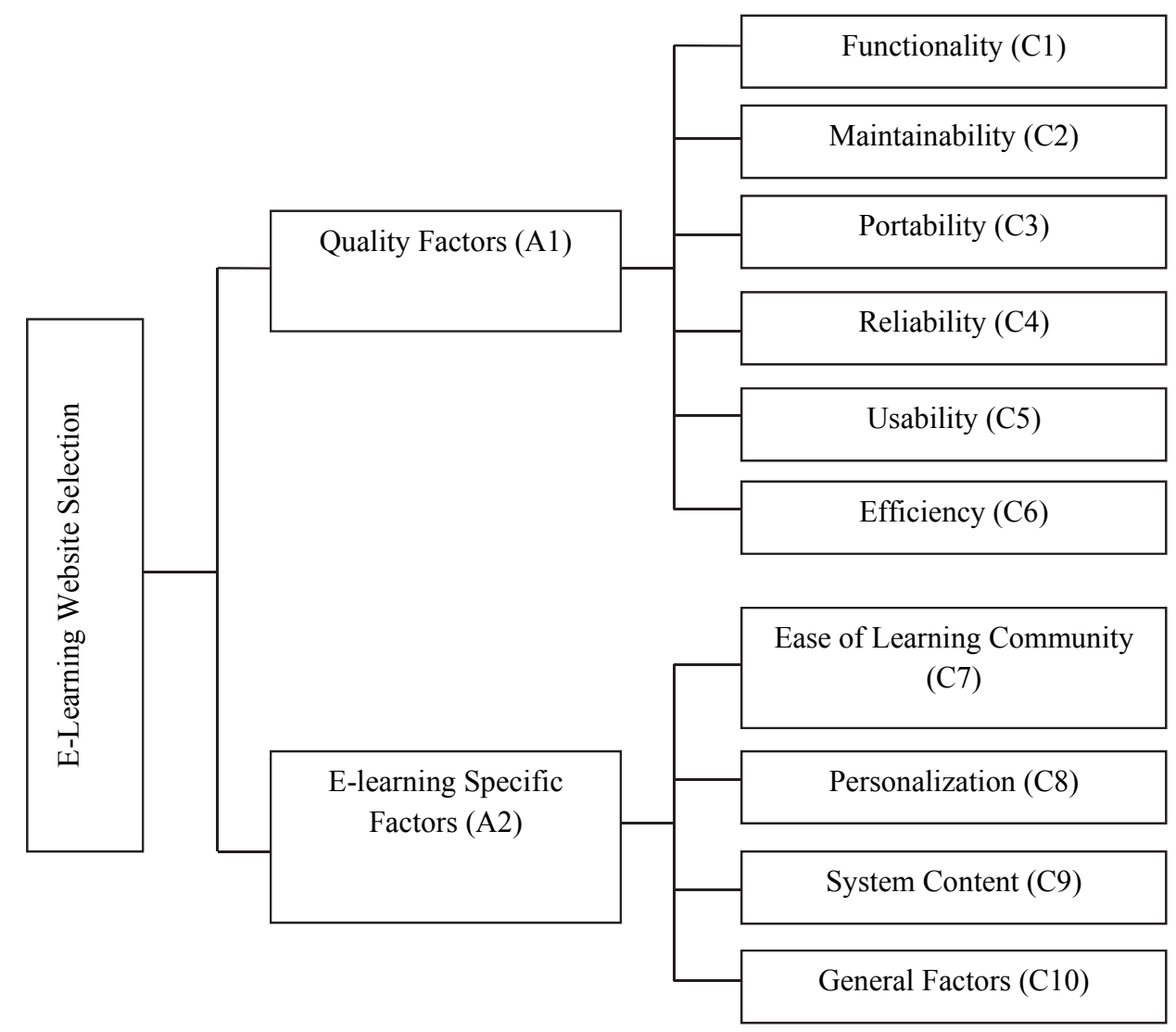

Fig. 3. Hierarchical structure of the selection indexes

\subsection{Calculation of selection indexes weights}

Based on the hierarchical structure of the selection indexes, the weights were calculated by applying FAHP. Firstly, the experts were asked to provide the desired data in the form of linguistic terms through a questionnaire. Now, the data obtained in the linguistic terms was converted in triangular fuzzy numbers and the weights of selection indexes were calculated using Eq. (2) and Eq. (3) and are provided in Table 2. The results in this table shows the critical order of the two perspective related to the Elearning websites selection considered in this study is "A1: Quality factors (0.74) and "A2: E-learning Specific factors (0.26). It depicts that the "Quality factors" selection index can play more significant role in the selection of E-learning websites as compare to "E-learning specific factors" selection index. 
Table 2

Weights of E-learning websites selection index by FAHP

\begin{tabular}{lllll}
\hline Index & \multirow{2}{*}{ Local Weight } & \multirow{2}{*}{ Sub-Index } & $\begin{array}{l}\text { Local } \\
\text { Weight }\end{array}$ & $\begin{array}{l}\text { Global } \\
\text { Weight }\end{array}$ \\
\hline Quality Factors & & Functionality & 0.39 & 0.29 \\
& \multirow{2}{*}{0.74} & Maintainability & 0.24 & 0.18 \\
& & Portability & 0.17 & 0.13 \\
& & Reliability & 0.05 & 0.04 \\
& & Usability & 0.05 & 0.04 \\
& & Efficiency & 0.09 & 0.07 \\
E-Learning Specific Factors & & & 0.47 & 0.12 \\
& \multirow{2}{*}{0.26} & Ease of Learning Community & 0.28 & 0.07 \\
& & Personalization & 0.13 & 0.03 \\
& & System Content & 0.13 & 0.03 \\
\hline
\end{tabular}

\subsection{Ranking of E-learning websites}

In the present research, eight ' $\mathrm{C}$ ' programming language websites (www.cprogramming.com, www.howstuffworks.com,www.programiz.com,www.geeksforgeeks.org,www.tutorialspoint.com, www.cs.cf.ac.uk, www.fresh2refresh.com and www.cprogrammingexpert.com) were evaluated by the experts committee based on the 10 selection indexes. ' $\mathrm{C}$ ' programming language is the oldest and most commonly used language for the software development and covered by most of the academic institutions in their curriculum. To get the ratings of each website, experts provided the data in the linguistic terms on a 10-point fuzzy scale and then these linguistic terms were converted into single numeric values using fuzzy operations. The fuzzy scale has been used and the final ratings of all eight E-learning websites are given in Table 3 and Table 4, respectively.

\section{Table 3}

Linguistic variables for ratings of alternatives

\begin{tabular}{lclcc}
\hline Linguistic Variables & Membership Functions & Linguistic Variables & Membership Functions \\
\hline Extremely More Important (EMI) & $(9,10,10)$ & Less Important (LI) & $(4,5,6)$ \\
Very Very More Important (VVMI) & $(8,9,10)$ & Very Less Important (VLI) & $(3,4,5)$ \\
Very More Important (VMI) & $(7,8,9)$ & Very Very Less Important (VVLI) & $(2,3,4)$ \\
More Important (MI) & $(6,7,8)$ & Extremely Less Important (ELI) & $(1,2,3)$ \\
Important (I) & $(5,6,7)$ & Not Important (NI) & $(1,1,2)$ \\
\hline
\end{tabular}

Table 4

Ratings of ' $\mathrm{C}$ ' programming websites

\begin{tabular}{llllllllllll}
\hline Label & 'C' Programming Websites & C1 & C2 & C3 & C4 & C5 & C6 & C7 & C8 & C9 & C10 \\
\hline CPW-1 & www.cprogramming.com & 8.20 & 8.20 & 7.40 & 8.20 & 8.40 & 7.80 & 7.40 & 6.80 & 7.40 & 8.53 \\
CPW-2 & www.howstuffworks.com & 4.26 & 4.06 & 4.26 & 4.06 & 3.20 & 3.20 & 4.26 & 4.06 & 4.06 & 4.26 \\
CPW-3 & www.programiz.com & 7.60 & 7.80 & 7.80 & 7.20 & 7.40 & 7.80 & 8.20 & 8.40 & 8.13 & 7.60 \\
CPW-4 & www.geeksforgeeks.org & 5.00 & 6.20 & 6.20 & 5.40 & 5.80 & 6.00 & 5.20 & 4.20 & 4.40 & 4.20 \\
CPW-5 & www.tutorialspoint.com & 8.73 & 8.93 & 8.87 & 8.40 & 8.87 & 8.60 & 8.87 & 7.80 & 8.20 & 8.40 \\
CPW-6 & www.cs.cf.ac.uk & 6.60 & 7.00 & 7.60 & 5.80 & 6.40 & 6.40 & 6.40 & 6.60 & 6.40 & 6.40 \\
CPW-7 & www.fresh2refresh.com & 8.53 & 8.20 & 8.87 & 8.53 & 8.60 & 8.73 & 8.00 & 8.33 & 8.20 & 7.60 \\
CPW-8 & www.cprogrammingexpert.com & 4.80 & 5.00 & 4.80 & 5.00 & 4.13 & 4.80 & 4.13 & 5.00 & 4.13 & 4.13 \\
\hline
\end{tabular}

Consequently, the three MADM analytical methods COPRAS, VIKOR and WDBA were applied to rank these eight E-learning websites and the rankings obtained are provided in Table 5 to Table 7 , respectively. 
Table 5

Rankings of E-learning websites obtained using COPRAS

\begin{tabular}{lllll}
\hline Label & 'C' Programming Websites & $\mathrm{P}_{\mathrm{i}}$ & $\mathrm{F}_{\mathrm{i}}$ & Rank \\
\hline CPW-1 & www.cprogramming.com & 0.14070 & 91.0645 & 3 \\
CPW-2 & www.howstuffworks.com & 0.09061 & 58.6443 & 8 \\
CPW-3 & www.programiz.com & 0.14037 & 90.8511 & 4 \\
CPW-4 & www.geeksforgeeks.org & 0.10411 & 67.3848 & 6 \\
CPW-5 & www.tutorialspoint.com & 0.15450 & 100.0000 & 1 \\
CPW-6 & www.cs.cf.ac.uk & 0.12451 & 80.5893 & 5 \\
CPW-7 & www.fresh2refresh.com & 0.14985 & 96.9853 & 2 \\
CPW-8 & www.cprogrammingexpert.com & 0.09535 & 61.7104 & 7 \\
\hline
\end{tabular}

To check the relationship between the rankings obtained from three methods namely, COPRAS, VIKOR and WDBA, Spearman's rank co-relation test were performed. The statistics of this test are provided in Table 8 that depicts that there was no significant difference between the rankings. Further, Spearman rank correlation was calculated as $1.000,0.976$ and 0.976 respectively that shows the positive relationship between these three rankings.

Table 6

Rankings of E-learning websites obtained using VIKOR

\begin{tabular}{llllll}
\hline Label & 'C' Programming Websites & $\mathrm{U}_{\mathrm{i}}$ & $\mathrm{R}_{\mathrm{i}}$ & $\mathrm{S}_{\mathrm{i}}$ & $\mathrm{Rank}$ \\
\hline CPW-1 & www.cprogramming.com & 0.18968 & 0.04145 & 0.14641 & 3 \\
CPW-2 & www.howstuffworks.com & 0.99582 & 0.29000 & 1.00000 & 8 \\
CPW-3 & www.programiz.com & 0.20310 & 0.07331 & 0.21006 & 4 \\
CPW-4 & www.geeksforgeeks.org & 0.72012 & 0.24199 & 0.77406 & 6 \\
CPW-5 & www.tutorialspoint.com & 0.01337 & 0.00968 & 0.00000 & 1 \\
CPW-6 & www.cs.cf.ac.uk & 0.43581 & 0.13819 & 0.44421 & 5 \\
CPW-7 & www.fresh2refresh.com & 0.07136 & 0.02698 & 0.06037 & 2 \\
CPW-8 & www.cprogrammingexpert.com & 0.86410 & 0.25497 & 0.87047 & 7 \\
\hline
\end{tabular}

Table 7

Rankings of E-learning websites obtained using WDBA

\begin{tabular}{llll}
\hline Label & 'C' Programming Websites & Suitability Index & Rank \\
\hline CPW-1 & www.cprogramming.com & 1.70806 & 4 \\
CPW-2 & www.howstuffworks.com & 8.06202 & 8 \\
CPW-3 & www.programiz.com & 1.69429 & 3 \\
CPW-4 & www.geeksforgeeks.org & 5.92277 & 6 \\
CPW-5 & www.tutorialspoint.com & 0.35827 & 1 \\
CPW-6 & www.cs.cf.ac.uk & 3.66131 & 5 \\
CPW-7 & www.fresh2refresh.com & 0.81670 & 2 \\
CPW-8 & www.cprogrammingexpert.com & 6.98435 & 7 \\
\hline
\end{tabular}

Table 8

Ranking results with their differences of COPRAS, VIKOR and WDBA method

\begin{tabular}{|c|c|c|c|c|c|c|c|c|c|}
\hline \multirow[b]{2}{*}{ Label } & \multicolumn{2}{|c|}{ COPRAS method } & \multicolumn{2}{|c|}{ VIKOR method } & \multicolumn{2}{|c|}{ WDBA method } & \multirow[b]{2}{*}{$\mathrm{D}=\mathrm{A}-\mathrm{B}$} & \multirow[b]{2}{*}{$\mathrm{D}=\mathrm{B}-\mathrm{C}$} & \multirow[b]{2}{*}{$\mathrm{D}=\mathrm{A}-\mathrm{C}$} \\
\hline & Score Value & $\begin{array}{l}\text { Rank } \\
\text { (A) }\end{array}$ & $\begin{array}{l}\text { Score } \\
\text { Value }\end{array}$ & $\begin{array}{l}\text { Rank } \\
\text { (B) }\end{array}$ & $\begin{array}{l}\text { Score } \\
\text { Value }\end{array}$ & $\begin{array}{l}\text { Rank } \\
\text { (C) }\end{array}$ & & & \\
\hline CPW-1 & 91.0645 & 3 & 0.14641 & 3 & 1.70806 & 4 & 0 & -1 & -1 \\
\hline CPW-2 & 58.6443 & 8 & 1.00000 & 8 & 8.06202 & 8 & 0 & 0 & 0 \\
\hline CPW-3 & 90.8511 & 4 & 0.21006 & 4 & 1.69429 & 3 & 0 & 1 & 1 \\
\hline CPW-4 & 67.3848 & 6 & 0.77406 & 6 & 5.92277 & 6 & 0 & 0 & 0 \\
\hline CPW-5 & 100.0000 & 1 & 0.00000 & 1 & 0.35827 & 1 & 0 & 0 & 0 \\
\hline CPW-6 & 80.5893 & 5 & 0.44421 & 5 & 3.66131 & 5 & 0 & 0 & 0 \\
\hline CPW-7 & 96.9853 & 2 & 0.06037 & 2 & 0.81670 & 2 & 0 & 0 & 0 \\
\hline CPW-8 & 61.7104 & 7 & 0.87047 & 7 & 6.98435 & 7 & 0 & 0 & 0 \\
\hline
\end{tabular}




\section{Discussions}

The present research emphasizes on the performance analysis of eight E-learning websites related to ' $\mathrm{C}$ ' programming language based on ten selection indexes. The FAHP method was employed to get the weights of the selection indexes and then three methods namely, COPRAS, VIKOR and WDBA were implemented to get the rankings of each E-learning website. Based on the results obtained, some major findings of the research were discussed as given below. The FAHP adopted in this study combines the traditional AHP with the FST that makes it capable to deal with the vagueness of data. The result of the FAHP analysis depicts as shown in Table 2 that "Quality factors" are more important having weight 0.74 as compare to the "E-learning specific factors" with weight 0.26 in the evaluation and selection process of E-learning websites. In addition, according to the COPRAS method, the alternative i.e. ' $\mathrm{C}$ ' programming language website having the maximum score value is ranked at first position and the minimum score value is ranked at last position. The ranking results of COPRAS method is presented in Table 5 that depicts that the ' $\mathrm{CPW}-5$ ' (www.tutorialspoint .com) is ranked at first position due to maximum score value i.e. 100.000 whereas the 'CPW-2' (www. Howstuffwroks.com) is ranked at last eighth position i.e. last due to minimum score value i.e. 58.644. According to the VIKOR and WDBA methodologies, the alternative i.e. ' $\mathrm{C}$ ' programming language website having the maximum score value is ranked at last position and the minimum score value is ranked at first position. The ranking results of VIKOR and WDBA methodologies are presented in Table 6 and Table 7 that depicts that the 'CPW5 ' is again ranked at first position due to minimum score value whereas the ' $\mathrm{CPW}-2$ ' is ranked at eighth position i.e. last due to maximum score value. The comparative rankings of three MADM methodologies adopted in this research are also provided in Fig. 4.

$\because \mathrm{COPRAS} \quad \square$ VIKOR $\quad$ WDBA

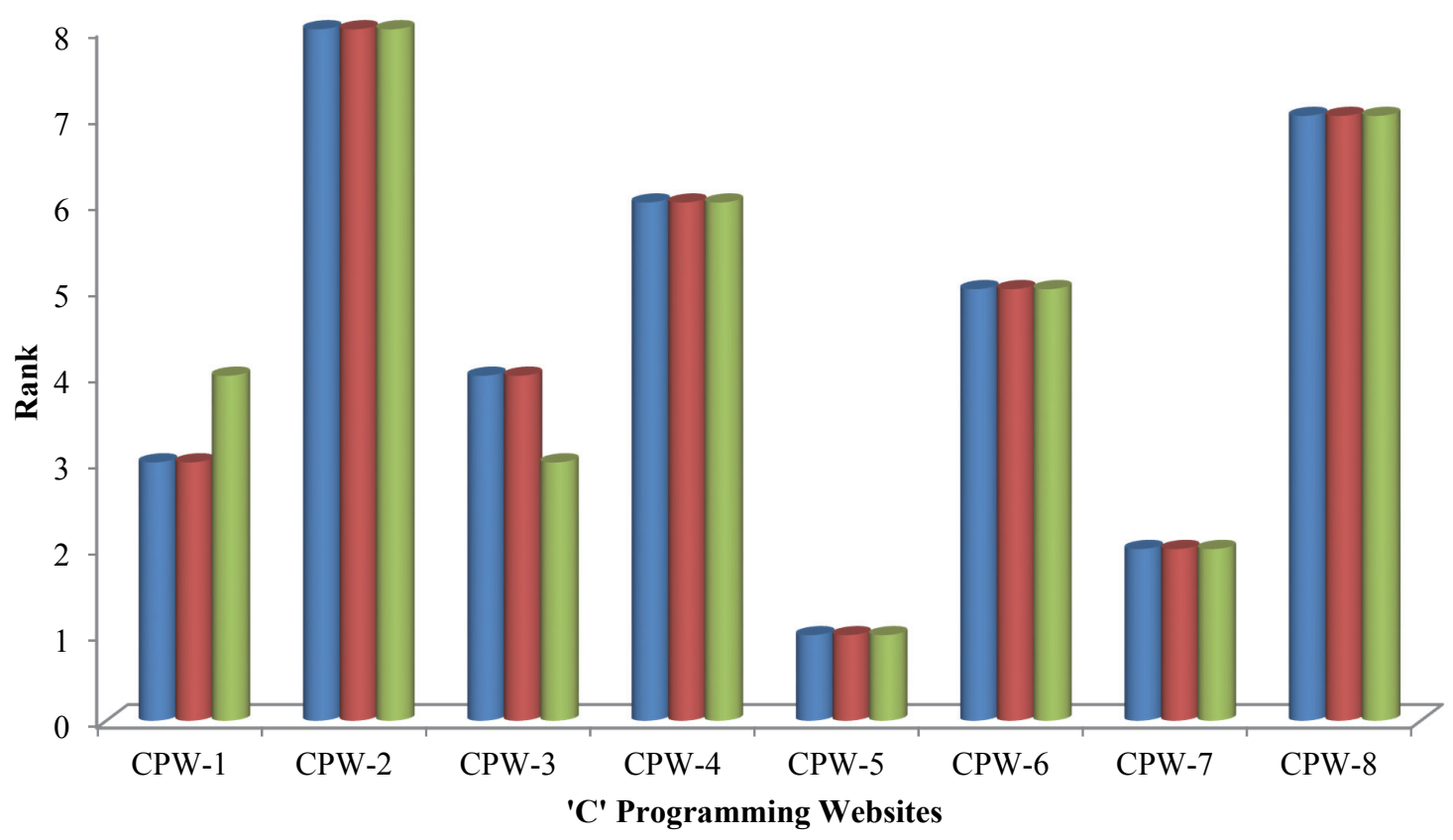

Fig. 4. Comparative rankings obtained using COPRAS, VIKOR and WDBA

\section{Conclusion and remarks}

There is no doubt that the various real life problems can be dealt as a multi-attribute decision making problems (Garg et al., 2007,2013; Jarial and Garg, 2012). The aim of the present study was to select 
the suitable ' $\mathrm{C}$ ' programming language E-learning website from a large number of ' $\mathrm{C}$ ' programming websites alternatives using the three MADM methodologies, namely COPRAS, VIKOR and WDBA methods which can be used as a benchmark to select the suitable ' $\mathrm{C}$ ' programming language website. Firstly, the weights of the selection indexes were calculated using the FAHP method. Secondly, three MCDM methodologies, namely COPRAS, VIKOR and WDBA were adopted to solve the ' $C$ ' programming language website problem. The ranking order of ' $\mathrm{C}$ ' programming language website using the COPRAS and VIKOR method are CPW-5 $>$ CPW-7 $>$ CPW $-1>$ CPW-3 $>$ CPW- $>$ CPW -4 $>\mathrm{CPW}-8>\mathrm{CPW}-2$ and the ranking order of ' $\mathrm{C}$ ' programming language website using the WDBA method is CPW-5 $>$ CPW-7 $>$ CPW-3 $>$ CPW-1 $>$ CPW-6 $>$ CPW-4 $>$ CPW-8 $>$ CPW-2. Hence, it concludes that the ' $\mathrm{CPW}-5$ ' (www.tutorialspoint.com) is most suitable ' $\mathrm{C}$ ' programming language website and 'CPW-2' (www. Howstuffwroks.com) is least suitable ' $\mathrm{C}$ ' programming language website. For further research, the results obtained from the present study can be compared with the other multi-attribute decision making methods.

\section{Acknowledgemen}

The authors would like to thank the anonymous referees for constrictive comments on earlier version of this paper.

\section{References}

Alias, N., Zakariah, Z., Ismail, N. Z., \& Aziz, M. N. A. (2012). E-Learning successful elements for higher learning institution in Malaysia. Procedia-Social and Behavioral Sciences, 67, 484-489.

Aparicio, M., Bacao, F., \& Oliveira, T. (2016). An e-Learning Theoretical Framework. Journal of Educational Technology \& Society, 19(1), 292-307.

Cheawjindakarn, B., Suwannatthachote, P., \& Theeraroungchaisri, A. (2013). Critical success factors for online distance learning in higher education: A review of the literature. Creative Education, 3(8), 61.

Covella, G. J., \& Olsina Santos, L. A. (2002). Specifying quality characteristics and attributes for ELearning sites. In IV Workshop de Investigadores en Ciencias de la Computación.

Ehlers, U. D. (2004). Quality in e-learning from a learner's perspective. European Journal of Open, Distance and E-learning, 7(1).

FitzPatrick, T. (2012). Key Success Factors of eLearning in Education: A Professional Development Model to Evaluate and Support eLearning. Online Submission.

Garg, R. K., Gupta, V. K., \& Agrawal, V. P. (2007). Quality evaluation of a thermal power plant by graph-theoretical methodology. International journal of power \& energy systems, 27(1), 42.

Garg, R. K., Sharma, K., Nagpal, C. K., Garg, R., Garg, R., \& Kumar, R. (2013). Ranking of software engineering metrics by fuzzy-based matrix methodology. Software Testing, Verification and Reliability, 23(2), 149-168.

Gupta, A., Garg, R. K., \& Tewari, P. C. (2013). Multi-Criteria Ranking of Inventory Ordering Policies Using Fuzzy Based-Distance Based Approach for Indian Automotive Industry. i-Manager's Journal on Management, 8(1), 41.

Garg, R., Sharma, R., \& Sharma, K. (2016). Ranking and selection of commercial off-the-shelf using fuzzy distance based approach. Decision Science Letters, 5(2), 201-210.

Govindasamy, T. (2001). Successful implementation of e-learning: Pedagogical considerations. The Internet and Higher Education, 4(3), 287-299.

Jain, D., Garg, R., Bansal, A., \& Saini, K. K. (2016). Selection and ranking of E-learning websites using weighted distance-based approximation. Journal of Computers in Education, 3(2), 193-207.

Jarial, S. K., \& Garg, R. K. (2012). Ranking of vendors based on criteria by MCDM-matrix method-a case study for commercial vehicles in an industry. International Journal og Latestest Research in Science and Technoly, 1(4), 337-341. 
Le Blanc, A., \& Wands, M. (2001). Critical success factors: e-learning solutions cappuccino. The official E-Newsletter of the Change and Learning Practice, 2.

Mosakhani, M., \& Jamporazmey, M. (2010, September). Introduce critical success factors (CSFs) of elearning for evaluating e-learning implementation success. In Educational and Information Technology (ICEIT), 2010 International Conference on (Vol. 1, pp. V1-224). IEEE.

Mahanta, D., \& Ahmed, M. (2012). E-Learning objectives, methodologies, tools and its limitation. International Journal of Innovative Technology and Exploring Engineering (IJITEE), 2, 46-51.

Opricovic, S. (1998). Multicriteria optimization of civil engineering systems. Faculty of Civil Engineering, Belgrade, 2(1), 5-21.

Ozkan, S., \& Koseler, R. (2009, October). Multi-dimensional evaluation of E-learning systems in the higher education context: an empirical investigation of a computer literacy course. In Frontiers in Education Conference, 2009. FIE'09. 39th IEEE (pp. 1-6). IEEE.

Oztekin, A., Delen, D., Turkyilmaz, A., \& Zaim, S. (2013). A machine learning-based usability evaluation method for eLearning systems. Decision Support Systems, 56, 63-73.

Öztürk, Z. K. (2014). Using A Multi Criteria Decision Making Approach For Open And Distance Learning System Selection. Anadolu University Journal of Science and Technology-An Applied Sciences And Engineering, 15(1), 1-14.

Plantak Vukovac, D., Kirinic, V., \& Klicek, B. (2010). A comparison of usability evaluation methods for e-learning systems. DAAAM International Scientific Book, 271-288.

Pruengkarn, R., Praneetpolgrang, P., \& Srivihok, A. (2005, July). An evaluation model for e-learning Websites in Thailand University. In Advanced Learning Technologies, 2005. ICALT 2005. Fifth IEEE International Conference on (pp. 161-162). IEEE.

Rao, R. (2012). Weighted Euclidean distance based approach as a multiple attribute decision making method for plant or facility layout design selection. International Journal of Industrial Engineering Computations, 3(3), 365-382.

Sela, E., \& Sivan, Y. Y. (2009). Enterprise e-learning success factors: An analysis of practitioners' perspective (with a downturn addendum).Interdisciplinary Journal of E-Learning and Learning Objects, 5(1), 335-343.

Selim, H. M. (2007). Critical success factors for E-learning acceptance: Confirmatory factor models. Computers \& Education, 49(2), 396-413.

Soong, M. B., Chan, H. C., Chua, B. C., \& Loh, K. F. (2001). Critical success factors for on-line course resources. Computers \& Education, 36(2), 101-120.

Saaty, T.L. (1980). The analytic hierarchy process. New York: McGraw-Hill, 1980.

Volery, T., \& Lord, D. (2000). Critical success factors in online education. International Journal of Educational Management, 14(5), 216-223.

Xaymoungkhoun, O., Bhuasiri, W., Rho, J. J., Zo, H., \& Kim, M. G. (2012). The critical success factors of e-learning in developing countries. Korea, 305, 701.

Yunus, Y., \& Salim, J. (2013). E-learning evaluation in Malaysian public sector from the pedagogical perspective: towards e-learning effectiveness. Journal of Theoretical \& Applied Information Technology, 51(2).

Zadeh L. A. (1965). Fuzzy sets. Information and Control, 8, 338-353.

Zaman, W., Ghosh, P., Datta, K., \& Basu, P. N. (2012). A Framework to Incorporate Quality Aspects for e-Learning System in a Consortium Environment. International Journal of Information and Education Technology, 2(2), 159.

Zavadskas, E. K., Kaklauskas, A., \& Sarka, V. (1994). The new method of multi-criteria complex proportional assessment of projects. Technological and Economic Development of Economy, 1(3), 131-139. 
(C) 2017 by the authors; licensee Growing Science, Canada. This is an open access article distributed under the terms and conditions of the Creative Commons Attribution (CC-BY) license (http://creativecommons.org/licenses/by/4.0/). 